\title{
INTEGRATED AGENT-ORIENTED MODELING AND SIMULATION OF POPULATION AND HEALTHCARE DELIVERY NETWORK: APPLICATION TO COPD CHRONIC DISEASE IN A CANADIAN REGION
}

\author{
Moez Charfeddine \\ Benoit Montreuil \\ CIRRELT Research Center \\ Faculty of Administration Sciences, Laval University \\ Pavillon Palasis-Prince, 2325, rue de la Terrasse \\ Quebec (Quebec), G1V 0A6, CANADA
}

\begin{abstract}
In this paper we introduce a framework for integrated agent-oriented modeling and simulation of the population with a specific chronic disease in a large region and of the network providing relevant healthcare services for this population. We illustrate the framework through the Chronic Obstructive Pulmonary Disease (COPD) population and healthcare delivery network in Quebec's capital region of Canada. In this framework exploiting agent oriented modeling, demand for healthcare is expressed deeply through the stochastic modeling of health status evolution of each person in a population of potential patients, where the implications of this evolution generate the demand in terms of patient needs for healthcare and their frequency. In parallel, the organization and functioning of the healthcare delivery network is modeled with an adequate detail level. This is made possible by exploiting the richness of the agent paradigm and by introducing integration mechanisms binding the two model components.
\end{abstract}

\section{INTRODUCTION}

The use of simulation techniques in healthcare often confronts the high level of complexity and uncertainty characterizing this specific application domain. Thus, modelers have to make appropriate compromises in order to build reliable models taking into account the objectives and the efforts. The global purpose of our research is to elaborate a complete conceptual and methodological framework as a guideline for the development of integrated agent-based modeling and simulation of healthcare delivery systems.

In Montreuil et al. (2007), we presented a generic conceptual framework based on a three-level categorization of the major components that modelers should define in order to build any healthcare simulation model. It's called $\mathrm{AOE}^{2}$, in reference to the top level defined components that are: Agents (operational and managerial entities), Objects (physical and informational resources), Environment (describe the modeled milieu organizationally and behaviorally) and Experience (simulation model results and interface). In the second and third levels, each component is divided into two more specific sub-components with increasing level of granularity. Thus for example, the "Environment" component comprises the "System" and the "Scenario" sub-components. The "Scenario" sub-component, in its turn, is divided into "Events / Crises" (representing the perturbations that may occur in the simulated environment and that can influence other components of the system) and "Demand" (which refers to the simulation load that the system will undergo). The "System" sub-component is divided into "Networks" (defining the organization of the healthcare delivery system) and "Processes" (modeling sets of interrelated activities collectively intending to produce healthcare services). In this work, we will specifically focus on the "Network" 


\section{Charfeddine and Montreuil}

and "Demand" components and present an integrated agent-simulation model for chronic disease population and healthcare delivery network, in accordance with our vision of the global $\mathrm{AOE}^{2}$ framework. The model is developed using an agent-oriented methodological framework presented in Charfeddine and Montreuil (2010).

The paper is structured as follows. Section 2 presents a brief literature review of how demand for healthcare services and healthcare delivery networks are modeled in existing simulation studies. Section 3 introduces the generic concepts of our integrated agent-oriented simulation model. Section 4 gives an illustrative field application of the framework, which is the case of COPD disease in the Québec's capital region in Canada. Finally, in section 5, conclusion and future work related to our research are presented.

\section{LITERATURE REVIEW}

The use of simulation techniques as a modeling approach is ever more increasing in the healthcare domain since the last few decades. Jun, Jacobson, and Swisher (1999) presented an extensive literature review of such applications and classified them into two categories: management of patient flow and resource allocation. In a systematic review of the use and value of simulation in healthcare, Fone et al. (2003) enlarged this classification by adding other categories like infection and communicable diseases, costs and economic evaluation, and screening. More recently, Brailsford (2007) proposed a taxonomy of healthcare simulation models, specifically discrete-event simulation and systems dynamics, based on the level of detail on which the model is focusing. The author identified three main groups of models at the human body level, at the healthcare unit level, and at the system-wide level.

Throughout these different classifications, we can distinguish our two major components that each simulation model in healthcare domain must address with greater or less detail and depth: 1) the population generating the demand for healthcare services, and 2) the healthcare delivery network representing the organization of the healthcare system in order to satisfy the population demand.

Simulation studies focusing on population and demand components lie principally in the domains of economic, epidemiologic and clinical modeling. In economic models, healthcare is considered like any other product or service consumed by a person or a population. Thus, personal as well as population demand for healthcare is expressed as a quantity function depending on different determinants such as prices of healthcare services / supplies, age, education level, and so on. Economic simulation models aim generally to evaluate the economic impact of diseases and health policies. Examples of such studies for the specific case of COPD disease can be found in Rutten-van Molken and Lee (2006) which include those by Hoogendoorn et al. (2005) and Borg et al. (2007). Epidemiologic studies are interested in modelling the spread of infectious diseases and thus go deeply in capturing the disease specificities (Ekici, Keskinocak, and Swann 2008, Aleman et al. 2009, Araz et al. 2009, Koppenhaver et al. 2009). Clinical models go also deeply in the modeling of the disease progression and health status, but in a perspective of analyzing medical interventions or for medical training purposes (Dev et al. 2007). In most of these studies, the healthcare delivery network is modeled at a macro level which generally just permits to assess the costs and availabilities of healthcare services.

Simulation studies focusing on healthcare delivery networks are mainly based on modeling care processes, patient flows and available resources within healthcare supply chains and facilities such as hospitals, clinics and care units. We distinguish two main categories. First there are simulation models centered on one healthcare service or center, such as emergency centers (Takakuwa and Shiozaki 2004; Medeiros, Swenson and DeFlitch 2008), operating rooms (Ferrin et al. 2004, Vasilakis et al. 2006), intensive care units (Griffiths et al. 2005), outpatient clinics (Morrison and Bird 2003, Giachetti et al. 2005, Wijewickrama and Takakuwa 2005), and ancillary services (Osidach and Fu 2003, Wong et al. 2003). Second there are simulation models centered on multiple healthcare services such as Blasak et al. (2003) studying emergency and medical telemetry units, Ashton et al. (2005) dealing with multiples clinics and treatment rooms, and Kotiadis (2006) representing an integrated care network for elderly people. In most of these researches, population demand for healthcare services is expressed as the probability distribution 


\section{Charfeddine and Montreuil}

of the quantity or arrival time of each type of patients. These types are defined using some of patient's principal characteristics such as their priority within the system.

Despite the diversity of simulation models focusing on either the population or network components, we did not find studies exploiting at the same time the analysis capacity richness that in-depth models of each components are able to provide. This is most probably due to the huge efforts perceived to be needed to elaborate such models. However, we think that there are ways to build with reasonable efforts integrated models of population and healthcare delivery networks in which demand is expressed more deeply while, in parallel, the organization and functioning of the healthcare delivery network is captured with an adequate detail level.

\section{PRESENTATION OF THE INTEGRATED AGENT-ORIENTED SIMULATION MODEL}

As mentioned before, the two main differentiating facets of our integrated model are the population model and healthcare delivery network model. We present here the structure of each model as well as the integration concepts that are used to link both of them.

\subsection{Population model}

Simulation models of demand for healthcare can be expressed more deeply through the stochastic modeling of the health state evolution of each person (represented as an agent) in a population of potential and actual patients, where the implications of this evolution generates the demand in terms of patient needs for healthcare and their frequency. Thus, in our proposed approach, demand for healthcare is modeled through the exploitation of four main population levels: general population, vulnerable population, affected population and registered population.

Each person is modeled by a set of individual factors such as socio-demographics (age, gender, residence zone, educational level, income, employment status, etc.), organic systems / clinical characteristics representing his health state (weight, height, blood pressure, disease severity, etc.), capabilities (traveling easiness, autonomy, etc.) and lifestyle / behaviors (smoking status, nutritional habits, etc.).

The general population includes the set of persons representing the overall population. Its representation includes an evolution model using data on and prognoses of elements such as births, mortality and migration. It has also environmental factors determining its societal organization and context such as pollution and health policies.

A risk factor represents any element of the individual or environmental factors that is susceptible to cause a particular disease or any organic systems deficiency of a person. Each person in the population presenting one or more risk factors has a probability to be considered as vulnerable and consequently as susceptible to develop the disease. The set of such vulnerable persons defines the vulnerable population. The affected population includes the set of really affected persons. They evolve from the vulnerable population to the affected population according to probability transitions for each disease and each severity stage of the disease. These probabilities represent the prevalence (for the initial population generated in the beginning of the simulation) and the incidence (during the simulation) of each disease and each severity stage of the disease. They can be dependent on one or more individual and / or environmental factors (especially risk factors).

Depending on the specificities of the disease, some health state characteristics also evolve under the influence of particular events and conditions related to the progression of the disease. Thus, for example, each affected person has a probability of having his health state deteriorate and thus ending up with a more advanced stage disease, and even to die (more probable if he is already in a more severe stage). Inversely, an affected person has a probability of having his health state improved and switching to a less advanced disease stage, and potentially to recover if we are not in context of a chronic disease (more probable if he is already in a less severe stage).

Once an affected person uses healthcare services from the delivery network, he becomes part of the registered population. 


\section{Charfeddine and Montreuil}

\subsection{Healthcare delivery network model}

Our proposed healthcare delivery network model is based on our strategic mapping framework and agentoriented modeling methodology for healthcare delivery systems presented in Charfeddine and Montreuil $(2008,2010)$. Conventionally, a network is composed of nodes and inter-node links. In our framework, nodes correspond to Healthcare Service Centers (HSCs), which is a generic term that refers to any healthcare organizational entity (emergency, hospital, clinic, etc.). HSCs are responsible of delivering specific healthcare services, by making decisions and performing processes, using resources to do so. Depending on the model objectives, each HSC and its associated processes and resources are presented with less or more details. For example, at a high level, a service process is composed of the following activities: admission, waiting queue, service and discharge.

The main agents that are defined in our healthcare delivery network model and their roles are described in Table 1. Tasks and capabilities assigned to each agent are specific to each model application. As required, it is also possible to identify other agents such as "Information agents" which encapsulate medical knowledge. From an architectural point of view, we consider deliberative (cognitive) agents and reactive agents (details on these architectures are available in Wooldridge (2002) for example). Figure 1 presents the operational model of a HSC comprising the two agent societies.

Table 1: Agents composing the healthcare delivery network and their roles

\begin{tabular}{|l|l|}
\hline \multicolumn{1}{|c|}{ Agent } & \multicolumn{1}{c|}{ Role } \\
\hline Patient agent & Maintaining and improving his/her health status. \\
\hline Care provider agent & $\begin{array}{l}\text { Serving his/her patients by providing required } \\
\text { care. }\end{array}$ \\
\hline Access agent & $\begin{array}{l}\text { Answering appointment and admission demands } \\
\text { of patients giving the capacities and access mod- } \\
\text { alities of the center. }\end{array}$ \\
\hline Referring agent & $\begin{array}{l}\text { Responsible for patients discharge and referring } \\
\text { between centers }\end{array}$ \\
\hline Healthcare service agent & $\begin{array}{l}\text { Responsible for delivering the entire care service } \\
\text { according to a specific process. }\end{array}$ \\
\hline Healthcare center agent & $\begin{array}{l}\text { Responsible for delivering the services offered by } \\
\text { the center. }\end{array}$ \\
\hline
\end{tabular}

Two types of interactions between agents are considered: informational and physical. Resources can be of three types: human, material and informational. For more details on these concepts, see Charfeddine and Montreuil (2010). Furthermore, as the model takes into account the spatial accessibility to healthcare centers, each HSC has a geo-referenced location.

When they are within a HSC within the network, patients have probabilities of needing a reference to another service or HSC depending on their health status. These probabilities are defined by typical patient pathways. A margin of error can also be added to some transition probabilities to model the efficiency of the referring system and to enable evaluating its impact for example.

\subsection{Integrating population and healthcare delivery network models}

The efficiency of the healthcare delivery system and the minimization of costs of the services have positive effects on the consumption of the services by the population and consequently on its people's health state. Inversely, it is clear that population characteristics, behavior and disease specificities have impacts on the way people consume healthcare services and thus on the performance of the healthcare network delivering services to this population. 


\section{Charfeddine and Montreuil}

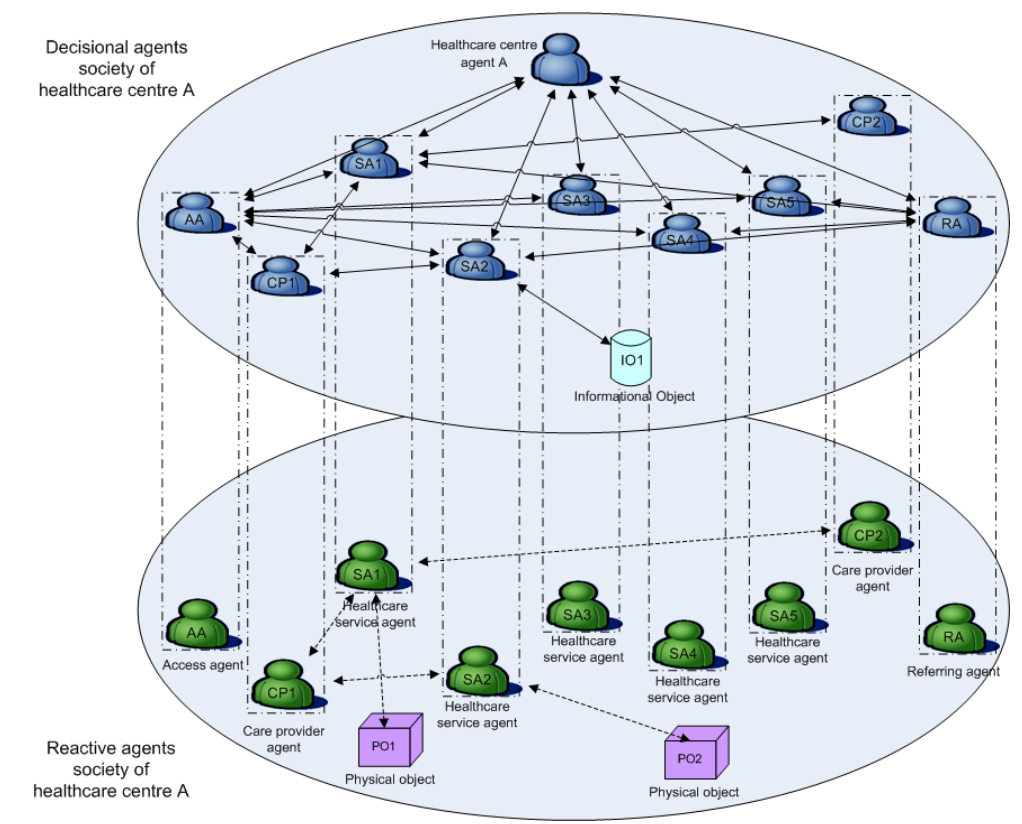

Figure 1: Agent-operational model representing a Healthcare Service Center

In order to reflect the impact of people behavior and disease progression on the way they consume healthcare services, we consider that each affected person may have different manifested disease symptoms that can evolve through time. When affected, each person may have a different behavior when facing his symptoms. This behavior depends on one or more socio-demographic characteristic(s) and on factors such as the nature, the number, and the severity of the symptoms. We identify the following typical profiles:

- Persons who are in an advanced stage of the disease (or having punctual periods of worsening symptoms manifestation) have highest probability of becoming urgent cases within our healthcare delivery network (i.e. trying immediately to get urgent services in the healthcare delivery system);

- Non-urgent cases that are prone to try to contact a healthcare provider immediately or at least within the next few hours or days by asking for accessible unscheduled or scheduled services;

- Non-urgent cases that are less tempted to call a healthcare provider; a varying delay is needed in this case before the persons try to ask for scheduled services of the healthcare delivery system.

In order to reflect the impact of the performance of the healthcare delivery network on the way people use the offered services and on their health state, we introduce the following concepts:

- A person trying to get services from a healthcare provider, or having decided to do so, will have a chance to succeed depending on the accessibility he has to the healthcare delivery network. This accessibility depends on some socio-demographic characteristics such as residence location, having or not a family physician, and so on. For these people, the health status evolution and behavioral profile model are again used to calculate how frequently they will return requesting care from the system.

- The probability that an affected person's health state will deteriorate are lower if the person was already diagnosed having the disease and is under treatment or followed by a health professional. Inversely, the probability that an affected person's health state will improve are higher if the person was already diagnosed having the disease and is under treatment or followed by a health professional.

- In a simulation experiment, an affected person should not be effectively recognized by the healthcare delivery system until he is diagnosed by a health professional as having the disease. 


\section{Charfeddine and Montreuil}

\section{APPLICATION TO THE CASE OF COPD DISEASE IN THE QUÉBEC'S CAPITAL REGION IN CANADA}

The modeling approach is illustrated using the example of COPD disease in Québec's capital region in Canada. The COPD is a non-reversible lung disease in which the lungs are damaged, making it hard to breathe (O'Donnell et al. 2007). The healthcare delivery network is administratively divided into four zones, each representing a local healthcare network coordinated by a CSSS (French acronym for Health and Social Services Center). These zones are: Vielle-Capitale, Québec-Nord, Charlevoix and Portneuf. The region covers a territorial area of 19,285 square kilometers. It deserves 57 municipalities, towns and villages. The overall region is also under the responsibility of the Agency of Health and Social Services of Capitale-Nationale, which is the regional authority coming under the Quebec's health and social services ministry.

\subsection{Data collecting methods}

An extensive data source review was performed in order to collect the data inputs feeding our agentoriented simulation model. Probabilities and statistics are derived from: 1) clinical and medical scientific studies about the COPD disease and its evolution (Garrido et al. 2006, Voll-Aanerud et al 2007a, 2007b), 2) field experts evaluation (lung specialists, clinical nurses specialized in COPD, health services managers), 3) official statistics of the healthcare governmental authorities (such as Quebec's health and social services ministry, Agency of health and social services responsible of Capitale-Nationale), and 4) data collected using the information system of Laval hospital in Québec City with the collaboration of our partners from this hospital.

Due to the important quantity of data needed for this type of population simulation model, it is not always easy to get the desired data at the desired detail level. Thus, we use the following approach: we start by searching specific data for the zone, then, if not available, for Québec capital region, then for the Québec province, then for Canada, then for occidental countries, then for other countries. If the data is not available with the desired dimension (for example, by age and not by sex) or for desired year, we make an extrapolation using the most suitable data available, while spotting it as data requiring sensitivity analysis and further investigation.

\subsection{Initial population and its projection}

Data that populates the model at the beginning of the simulation is defined to represent the whole population of the region using estimations of the initial population size for the base year and the repartition by zone, sex and age groups (e.g. five-year groups). More specifically, COPD affected persons at the beginning of the population are obtained from data on chronic disease prevalence.

Annual evolution of the population for the simulation period is derived from statistics on births, mortality and net migration for Québec province. The mortality (and its repartition by zone, sex and age group) is divided into mortality caused by COPD and mortality caused by other causes. The former is available directly from data on chronic diseases mortality. The later is calculated as the difference between the total mortality rate and the mortality rate due to COPD.

Since the simulation time unit is a day, we suppose that the total annual number of births, net migration and mortality due to other diseases than COPD are uniformly distributed along the days of a simulation year. Mortality due to COPD is a part of the disease evolution model of each affected person.

\subsection{Person / Patient model}

In this article, we use the term "person" for each individual in our population. When a person is affected by COPD disease and uses a healthcare service provided by the delivery network, such a person becomes a "patient". In the following subsections, we present the main components of the person / patient model. 


\section{Charfeddine and Montreuil}

Statecharts are used to present the evolution of the health status and the behavior of the person / patient agent.

\subsubsection{Demographics}

Socio-demographic characteristics considered in our COPD model are the following : age, gender, residence zone, home residence postal code, and educational level. Each person generated in the population has its own characteristics defined using transversal statistics of the studied population.

\subsubsection{Smoking status}

It is well recognized that smoking is the principle cause of COPD, indeed about $85 \%$ of occurrences (see for example O'Donnell et al. 2007). Thus, in our model, three categories of smoking status are considered: never-smoker, current-smoker and ex-smoker (see smoking status statechart in figure 2). Initial smoking status estimates are derived from data on population smoking prevalence by age group, sex and zone. Start, quit and restart smoking transition rates are obtained from studies analyzing population smoking behavior. They can be influenced also by prevention and education programs delivered by the network. Other factors that are potentially causal risk factors related to COPD are: exposure to pollutants and heredity, but these are not yet included in our current model.

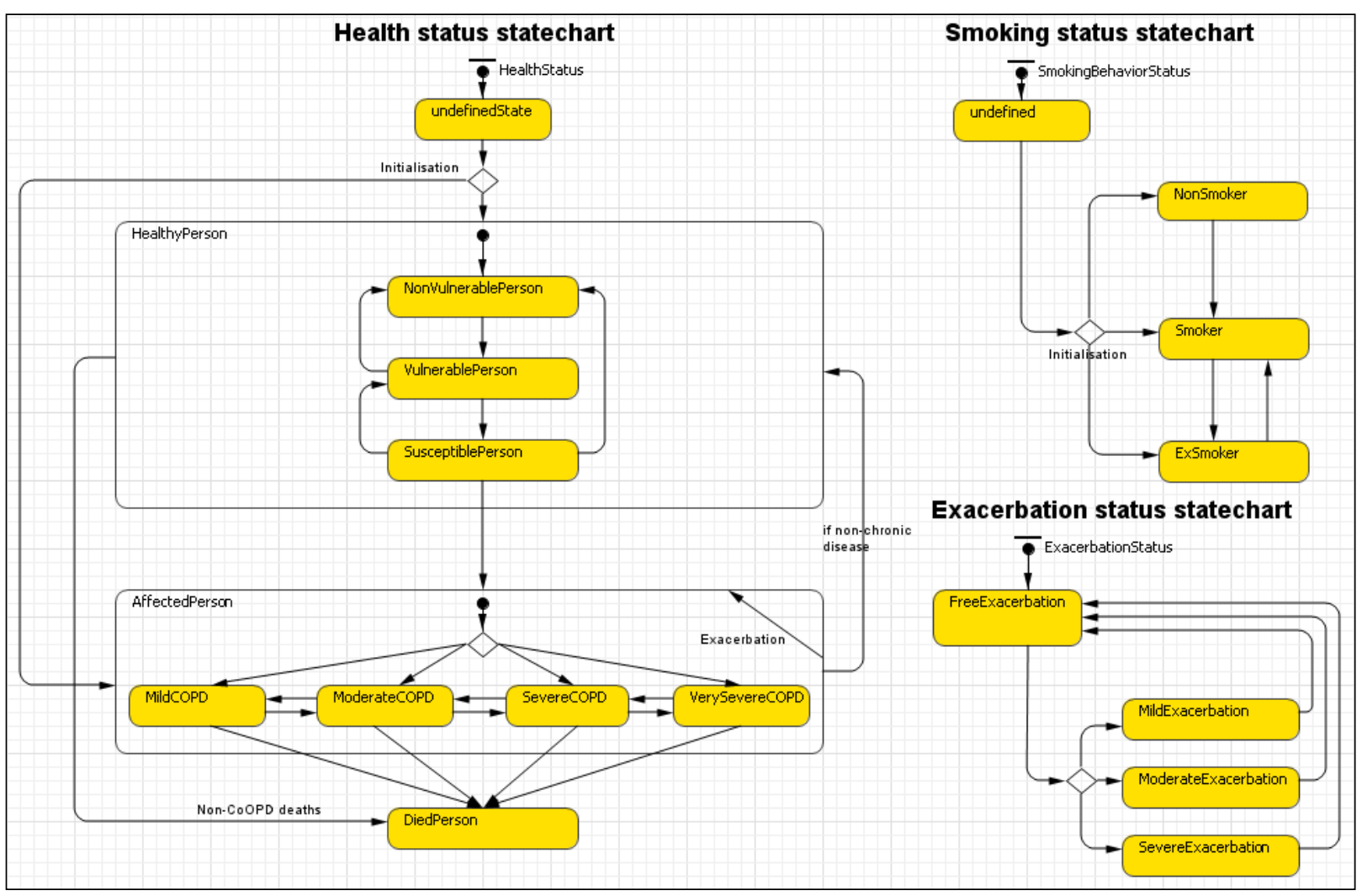

Figure 2: Statecharts representing Health status, Smoking status and Exacerbation status

\subsubsection{Health state : COPD severity and Exacerbations}

Since the model illustrated in this paper is specific to the COPD disease, we consider that the health state of each person in the population is, at the higher level, in one of the following states: healthy, COPD af- 


\section{Charfeddine and Montreuil}

fected or died. Healthy persons who are smokers or ex-smokers are considered as vulnerable persons. Vulnerable person have a certain probability to be susceptible to the development of COPD. These probabilities correspond to the incidence of the COPD disease and depend on sex, age group and smoking status. Susceptible persons develop COPD disease in a certain period of time according to a probability distribution, here simply estimated as uniformly distributed between one day and one year.

The principle health state characteristics for COPD affected persons in our model are COPD severity and exacerbations. COPD severity is defined by the lung function measured by the forced expiratory volume in the first second as a percentage of the predicted normal value (FEV1 predicted \%). According to the classification of Canadian Thoracic Society (O'Donnell et al. 2007), COPD severity is divided into four stages of severity: mild (FEV1 $\geq 80 \%)$, moderated $(50 \% \leq \mathrm{FEV} 1<80 \%)$, severe $(30 \% \leq \mathrm{FEV} 1<$ $50 \%$ ) and very severe (FEV1 $<30 \%$ ). Transition rates define the evolution of the health status of each affected person. As presented in figure 1, we suppose that transitions are possible only from one severity stage to an adjacent one, except for the death state. COPD exacerbation is a specific period of worsening symptoms. It can be divided into four states: free, mild, moderate and severe. Probabilities of occurrence, transition rates, and distribution of exacerbation duration are estimated based on the work of Borg et al. (2004).

COPD severity of each affected person in the beginning of simulation and when affected during the simulation are respectively derived from studies on the prevalence and incidence of COPD disease. Initial FEV1 estimates are generated using a normal distribution with a mean of 68.3 and a standard deviation of 19.9 (as reported in Hoogendoorn et al. 2005), truncated by the limits of each COPD severity stage of each affected person. Moreover, FEV1 can decline or increase due to the following events: start or stop smoking, receiving a treatment, getting an exacerbation.

\subsubsection{Patient capabilities and behaviors}

Exacerbations are considered as the most frequent cause of healthcare services utilization (medical visits and hospitalizations) and of increasing use of maintenance medications (O'Donnell et al. 2007). Thus, in our model, when feeling bad (COPD symptoms starting to appear, or in case of exacerbation), a person can have the following behaviors depending on the COPD severity or the exacerbation severity:

- Manage by himself his health state if he has already been educated to COPD self-management.

- Ask for a scheduled healthcare service. In this case, the patient calls for an appointment, waits for the appointment date and then goes to the healthcare center at the appointment date.

- Ask for an urgent or unscheduled service. In this case, the patient goes directly to the healthcare center he has targeted.

The patient chooses first a center offering the needed service from those which are geographically accessible to him (i.e. located in a certain distance radius from his residence postal code). If he does not find one, he chooses arbitrarily any other adequate center in his zone, if none then in the overall region.

When referred by a healthcare provider to another service, the patient calls for appointment to a center offering this service. If hospitalized, the patient stays in the hospital for the hospitalization period. When a visit to a center ends, a patient returns back home.

\subsubsection{Healthcare Service Centers}

A mapping study has permitted to identify the different providers of services related to COPD in Québec capital region. The types of HSC considered and their offered services are summarized in Table 2.

\subsubsection{Agents}

Given the objectives of the model, we defined the specific tasks that are assigned to the agents. These are summarized in table 3. 


\section{Charfeddine and Montreuil}

Table 2: Types of Healthcare Service Centers and their offered services

\begin{tabular}{|l|l|}
\hline \multicolumn{1}{|c|}{ HSC type } & \multicolumn{1}{c|}{ Services } \\
\hline Hospitalization units & Hospitalization \\
\hline Local community service center & COPD Follow-up \\
\hline Regional specialized respiratory home care service & Oxygen material providing \\
\hline Family physicians group & General consultation, COPD Follow-up \\
\hline Family physicians unity & General consultation, COPD Follow-up \\
\hline Medical clinic / office & General consultation, COPD Follow-up \\
\hline COPD clinic & COPD Education \\
\hline Pulmonary ambulatory clinic & $\begin{array}{l}\text { Specialized Consultation in pulmonary diseases }- \\
\text { Appointment within 24h }\end{array}$ \\
\hline Priority Pulmonary specialized clinic & Specialized Consultation in pulmonary diseases \\
\hline Emergency & Emergency care \\
\hline
\end{tabular}

Table 3: Agents composing the healthcare delivery network and associated tasks

\begin{tabular}{|l|l|}
\hline \multicolumn{1}{|c|}{ Agent } & \multicolumn{1}{c|}{ Tasks } \\
\hline Patient agent & - Detect the deterioration in his health status \\
& - Make self-management of his illness when possible \\
& - Decide to request a healthcare service (with or without appointment) \\
& - Choose a healthcare center offering the required service \\
& - Call for an appointment \\
& - Go to a healthcare center without an appointment or at the date of appointment \\
& - Go back home \\
& - Ask for a healthcare service or center when referred to by a care provider \\
\hline $\begin{array}{l}\text { Care provider } \\
\text { agent }\end{array}$ & - Pecide on the patient's suitable treatment \\
& - Decide whether to refer a patient to another healthcare service \\
\hline Access agent & - Receive a patient's call for appointment \\
& - Receive and direct a patient to the appropriate service \\
& - Maintain the appointments schedule of the center \\
& - Give an appointment to a patient as available in the planning \\
\hline Referring agent & - Check the constraints and criteria for referral of the referred center \\
& - Refer the patient to another healthcare service or center \\
\hline $\begin{array}{l}\text { Healthcare service } \\
\text { agent }\end{array}$ & $\begin{array}{l}\text { - Define and monitor the delivery process of the service care } \\
\text { - Assign a care provider and a medical equipment when required for a patient }\end{array}$ \\
\hline $\begin{array}{l}\text { Healthcare center } \\
\text { agent }\end{array}$ & $\begin{array}{l}\text { - Manage and allocate human and physical resources between services } \\
\text { - Manage collaboration with other centers }\end{array}$ \\
\hline
\end{tabular}

\subsubsection{Simulation prototype and experimentation}

To illustrate our integrated framework, we have developed an agent-oriented simulation prototype for the case of COPD model in Québec's capital region. We chose to use the AnyLogic $\mathbb{C}$ simulation platform, developed by XJ Technologies Company. This platform provides a Java-based software environment for the development of systems of discrete event simulation, model-based dynamic systems, agent-based and hybrid systems (Borshchev, Karpov, and Kharitonov 2002). AnyLogic $(\mathrm{C}$ provides a set of predefined and 


\section{Charfeddine and Montreuil}

customizable modeling elements that can be configured to build and expand its model simulation. It also includes a graphical editor for visual representation and animation of these different elements.

The complete description of the prototype components is beyond the scope of this article as well as the experimental investigations exploiting it. We describe here briefly the main interface of this prototype (Figure 3). This interface exhibits the four zones of the modeled region. The colored dots represent COPD affected patients whose color refers to the stage of disease severity (mild $=$ Yellow, moderate $=$ Orange, severe $=$ Red, very severe $=$ Purple). In fact, the whole population is modeled in the simulation as a society of agents, but for purposes of clarity, they are represented visually only when they become COPD affected. The colored diamonds represent the network's healthcare centers, their color identifying the center's type (e.g. green $=$ local community care center, blue $=$ clinic $/$ medical office, etc.). Various statistics are dynamically generated on the simulated population such as population distribution (by age, sex, zone, etc.), the distribution of COPD patients by stage of disease severity, etc. The use of this prototype will permit to experiment with different scenarios of network deployment, resources allocation, population projections, etc.

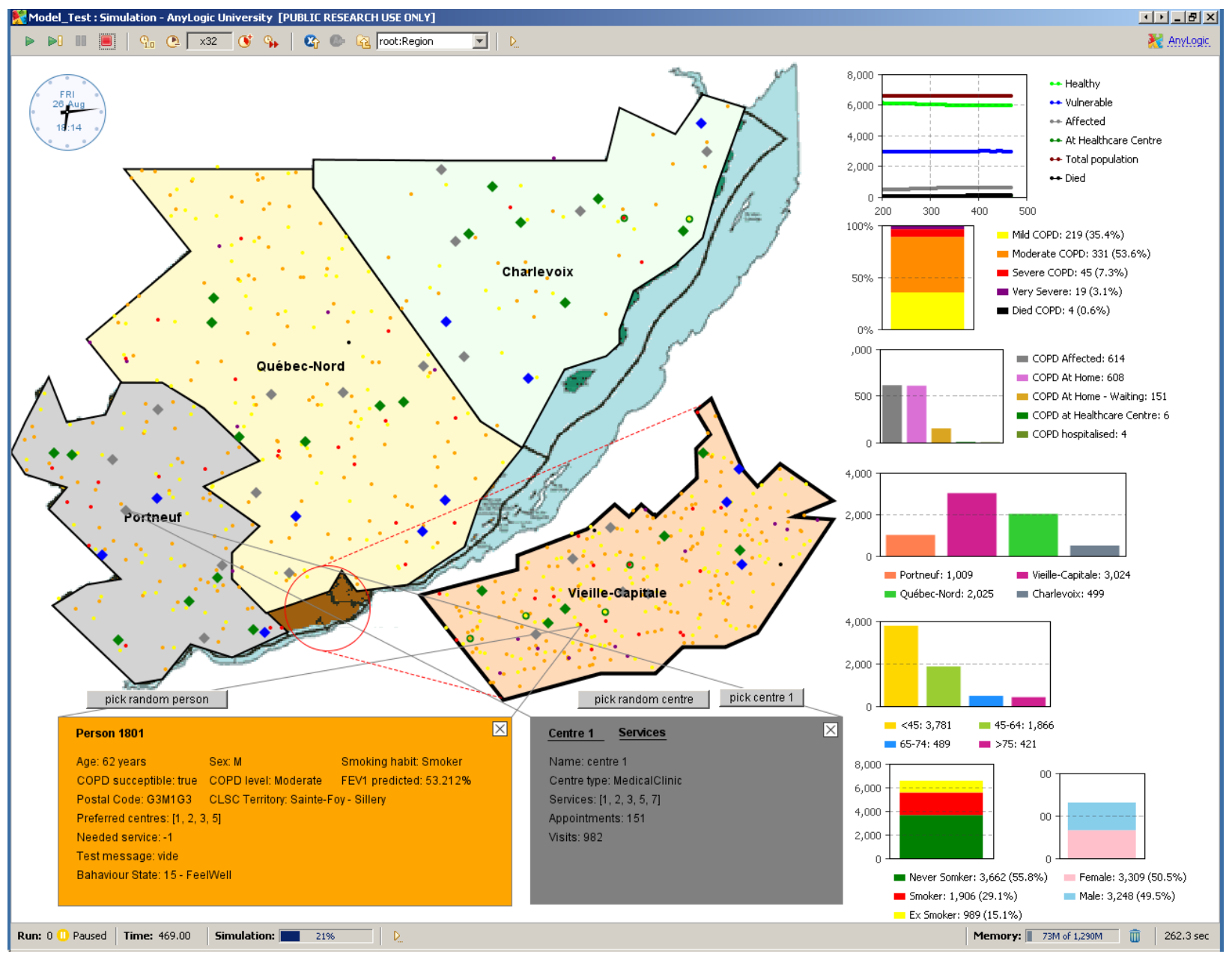

Figure 3: Main Interface of the simulation agent-oriented prototype for COPD in Québec's capital région

\section{CONCLUSION AND FUTURE WORK}

This work is a step forward towards the development of a global conceptual and methodological framework for integrated agent-oriented modeling and simulation of population and healthcare delivery sys- 


\section{Charfeddine and Montreuil}

tems. In the intended integrated models, demand is expressed deeply while, in parallel, the organization and functioning of the healthcare delivery network is captured with an adequate detail level. Such integrated models can become persistent models dynamically used in multiple contexts over a long horizon.

We are conscious that, in such an approach, consistent efforts are needed in order to collect needed data and to build reliable models of the disease progression and agents behaviors (patient, care providers, healthcare centers managers, etc.). In fact, the necessary research combines a quest for adapted clinical research and for information technology platforms supporting such approaches. Thus, the main future research avenues include: 1) improving the model as well as the clinical research about how COPD disease is evolving in a person, especially in response to treatments, 2) extending the illustrative field case in order to take into consideration more than one specific disease, as well as other regions, and 3) exploiting the COPD prototype in order to experiment with different scenarios of network deployment, disease treatment policies, resources allocation and population projections.

\section{ACKNOWLEDGMENTS}

We thank all the research team members from the University Institute of Cardiology and Pulmonology Of Québec (Laval Hospital): Dr Yves Lacasse, Hélène Boutin, Martin Lord, Michel Martineau, Mireille Ouellet and Rose-Anne Tremblay. This research has been financially supported by the Canada Research Chair in Enterprise Engineering.

\section{REFERENCES}

Aleman, D.M., T.G. Wibisono, B. Schwartz. 2009. Accounting for individual behaviors in a pandemic disease spread model. In Proceedings of the 2009 Winter Simulation Conference, ed. M.D. Rossetti, R.R. Hill, B. Johansson, A. Dunkin and R.G. Ingalls, 1977-1985. Piscataway, New Jersey: Institute of Electrical and Electronics Engineers, Inc.

Araz, O.M., J.W. Fowler, T.W. Lant and M. Jehn. 2009. A pandemic influenza simulation model for preparedness planning. In Proceedings of the 2009 Winter Simulation Conference, ed. M. D. Rossetti, R. R. Hill, B. Johansson, A. Dunkin and R. G. Ingalls, 1986 - 1995. Piscataway, New Jersey: Institute of Electrical and Electronics Engineers, Inc.

Ashton, R., L. Hague, M. Brandreth, D. Worthington, and S. Cropper. 2004. A simulation-based study of a NHS walk-in centre. Journal Operational Research Society 56:153-161.

Blasak, R.E., D.W. Starks, W.S. Armel, and M.C. Hayduk. 2003. Healthcare process analysis: the use of simulation to evaluate hospital operations between the emergency department and a medical telemetry unit. In Proceedings of 2003 Winter Simulation Conference, ed. S.E. Chick, P.J. Sanchez, D.M. Ferrin, and D.J. Morrice, 1887-1893. Piscataway, New Jersey: Institute of Electrical and Electronics Engineers, Inc.

Borshchev, A., Y. Karpov, and V. Kharitonov. 2002. Distributed simulation of hybrid systems with Anylogic and HLA. In the 6th International Conference on Parallel Computing Technologies 18(6): 829839.

Brailsford, S.C. 2007. Tutorial: advances and challenges in healthcare simulation modeling. In Proceedings of the 2007 Winter Simulation Conference, ed. S.G. Henderson, B. Biller, M.-H. Hsieh, J. Shortle, J.D. Tew, and R.R. Barton, 1436-1448. Piscataway, New Jersey: Institute of Electrical and Electronics Engineers, Inc.

Borg, S., A. Ericsson, J. Wedzicha, A. Gulsvik, B. Lundback, G.C. Donaldson, and S.D. Sullivan. 2004. A computer simulation model of the natural history and economic impact of chronic obstructive pulmonary disease. Value Health 7:153-167.

Charfeddine M., and B. Montreuil. 2008. Une approche de mappage stratégique de réseaux intégrés de santé (An approach for strategic mapping of integrated healthcare networks). GISEH Conference. 


\section{Charfeddine and Montreuil}

Charfeddine M. and B. Montreuil. 2010, Vers un cadre méthodologique de modélisation et de simulation orientée agent pour les systèmes de livraison de soins de santé (Towards a methodological framework for agent-oriented modeling and simulation of healthcare delivery networks). GISEH Conference.

Dev, P., W.L. Heinrichs, P. Youngblood, S. Kung, R. Cheng, L. Kusumoto, and A. Hendrick. 2007. Virtual patient model for multi-person virtual medical environments. In AMIA Annual Symposium Proceedings, 11:181-185.

Ekici, A., P. Keskinocak, J.L. Swann. 2008. Pandemic influenza response. In Proceedings of the 2008 Winter Simulation Conference, ed. S.J. Mason, R.R. Hill, L. Mönch, O. Rose, T. Jefferson, and J.W. Fowler, 1592-1600. Piscataway, New Jersey: Institute of Electrical and Electronics Engineers, Inc.

Fone, D., S. Hollinghurst, M. Temple, A. Round, N. Lester, A. Weightman, K. Roberts, E. Coyle, G. Bevan, and S. Palmer. 2003. Systematic review of the use and value of computer simulation modelling in population health and healthcare delivery. Journal of Public Health Medicine 25:325--335.

Ferrin, D.M., M.J. Miller, S. Wininger, and M.S. Neuendorf. 2004. Analyzing incentives and scheduling in a major metropolitan hospital operating room through simulation. In Proceedings of the $2004 \mathrm{Win}$ ter Simulation Conference, ed. R.G. Ingalls, M.D. Rossetti, J.S. Smith, and B.A. Peters, 889-894. Piscataway, New Jersey: Institute of Electrical and Electronics Engineers, Inc.

Garrido, C.P., J. de Miguel Diez, R.J. Gutierrez, et al. 2006. Negative impact of chronic obstructive pulmonary disease on the health-related quality of life of patients. Results of the EPIDEPOC study. Health Quality Life Outcomes 4:31.

Giachetti, R.E., E.A.Centeno, M.A. Centeno, and R. Sundaram. 2005. Assessing the viability of an open access policy in an outpatient clinic: a discrete-event and continuous simulation modeling approach. In Proceedings of the 2005 Winter Simulation Conference, ed. M.E. Kuhl, N.M. Steiger, F.B. Armstrong, and J.A. Joines, 2246-2255. Piscataway, New Jersey: Institute of Electrical and Electronics Engineers, Inc.

Griffiths, J.D., N. Price-Lloyd, M. Smithies, and J.E. Williams. 2005. Modeling the requirement for supplementary nurses in an intensive care unit. Journal of the Operational Research Society 56:126-133.

Hoogendoorn, M, M.P. Rutten-van Molken, R.T. Hoogenveen, M.L. van Genugten, A.S. Buist, E.F. Wouters, and T.L. Feenstra. 2005. A dynamic population model of disease progression in COPD. European Respiratory Journal 26:223-233.

Jun, J., S. Jacobson, and J. Swisher. 1999. Application of discrete-event simulation in health care clinics: A survey. Journal of the Operational Research Society 50:109-123.

Koppenhaver, R.T., A. Schaefer, R.S. Braithwaite, and M. Roberts. 2009. A simulation model of HIV treatment under drug scarcity constraints. In Proceedings of the 2009 Winter Simulation Conference, ed. M.D. Rossetti, R.R. Hill, B. Johansson, A. Dunkin and R.G. Ingalls, 2090 - 2095. Piscataway, New Jersey: Institute of Electrical and Electronics Engineers, Inc.

Kotiadis, K. 2006. Extracting a conceptual model for a complex integrated system in health care. In Proceedings of the OR Society's Two-Day Workshop (SW06), 235-245.

Medeiros, D.J., E. Swenson and C. DeFlitch. 2008. Improving patient flow in a hospital emergency department. In Proceedings of the 2008 Winter Simulation Conference, ed. S.J. Mason, R.R. Hill, L. Mönch, O. Rose, T. Jefferson, J.W. Fowler, 1526-1531. Piscataway, New Jersey: Institute of Electrical and Electronics Engineers, Inc.

Montreuil, B., M. Charfeddine, O. Labarthe, and A. Côté André. 2007. A generic agent-based framework for simulation in distributed healthcare systems. International Conference on Industrial Engineering and Systems Management.

Morrison, B.P., and B.C. Bird. 2003. Healthcare process analysis: a methodology for modeling front office and patient care processes in ambulatory health care. In Proceedings of 2003 Winter Simulation Conference, ed. S.E. Chick, P.J. Sanchez, D.M. Ferrin, and D.J. Morrice, 1882-1886. Piscataway, New Jersey: Institute of Electrical and Electronics Engineers, Inc. 


\section{Charfeddine and Montreuil}

O’Donnell, D.E., P. Hernandez, S. Aaron, J. Bourbeau, D. Marciniuk, R. Hodder et al. 2007. Canadian Thoracic Society recommendations for management of chronic obstructive pulmonary disease - 2007 update. Canadian Respiratory Journal 14(B):5-32.

Osidach, V.Z., and M.C. Fu. 2003. Public health: computer simulation of a mobile examination center. In Proceedings of 2003 Winter Simulation Conference, ed. S.E. Chick, P.J. Sanchez, D.M. Ferrin, and D.J. Morrice, 1868-1875. Piscataway, New Jersey: Institute of Electrical and Electronics Engineers, Inc.

Rutten-van Mölken, M., and T.A. Lee. 2006. Economic modeling in chronic obstructive pulmonary disease. In The Proceedings of the American Thoracic Society 3:630-634.

Takakuwa, S., and H. Shiozaki. 2004. Functional analysis for operating emergency department of a general hospital. In Proceedings of the 2004 Winter Simulation Conference, ed. R.G. Ingalls, M.D. Rossetti, J.S. Smith, and B.A. Peters, 917-925. Piscataway, New Jersey: Institute of Electrical and Electronics Engineers, Inc.

Vasilakis, C., B. Sobolev, L. Kuramoto and A.R. Levy.2006. A simulation study of scheduling clinic appointments in surgical care: individual-surgeon versus pooled lists. Journal of Operational Research Society 58:202-211.

Voll-Aanerud, M., T.M. Eagan, T. Wentzel-Larsen, et al. 2007a. Changes in respiratory symptoms and health-related quality of life. Chest Journal 131:1890-1897.

Voll-Aanerud, M., T.M. Eagan, T. Wentzel-Larsen, et al. 2007b. Respiratory symptoms, COPD severity, and health related quality of life in a general population sample. Respiratory Medicine 102:399-406.

Wijewickrama, A. and S. Takakuwa. 2005. Simulation analysis of appointment scheduling in an outpatient department of internal medicine. In Proceedings of the 2005 Winter Simulation Conference, ed. M.E. Kuhl, N.M. Steiger, F.B. Armstrong, and J.A. Joines, 2264-2273. Piscataway, New Jersey: Institute of Electrical and Electronics Engineers, Inc.

Wong, C., G. Geiger, Y.D. Derman, C.R. Busby, and M.W. Carter. 2003. Healthcare process analysis: redesigning the medication ordering, dispensing, and administration process in an acute care academic health sciences centre. In Proceedings of 2003 Winter Simulation Conference, ed. S.E. Chick, P.J. Sanchez, D.M. Ferrin, and D.J. Morrice, 1894-1902. Piscataway, New Jersey: Institute of Electrical and Electronics Engineers, Inc.

Wooldridge, M. 2002. An introduction to multiagent systems. Chichester, England: John Wiley \& Sons.

\section{AUTHOR BIOGRAPHIES}

MOEZ CHARFEDDINE is an engineer graduated from Polytechnic School of Tunisia in 2002. Since 2004, he has a MBA in information technology management from Université Laval, with an essay on appointment scheduling in health care centers. He is engaged in the Ph.D. program in administration sciences of Université Laval, with research focusing on modeling and simulation of healthcare delivery networks. He has extensive experience as an information technology consultant in both private and public sector. His email address is $<$ Moez. Charfeddinedcirrelt.ulaval.ca>.

BENOIT MONTREUIL is professor of operations and decisions systems in the administration sciences faculty of Université Laval in Quebec City, Canada, since 1988. He is a professional industrial engineer graduated in 1978 from Université du Québec à Trois-Rivières (UQTR). He holds a M.S.I.E. (1980) and a Ph.D. (1982) in Industrial Engineering from the Georgia Institute of Technology (Atlanta, U.S.A.). He holds the Canada Research Chair in Enterprise Engineering. He is a founding member of the CIRRELT Interuniversity Research Centre on Enterprise Networks, Logistics and Transportation. His main research interests lie in developing concepts, methodologies and technologies for creating, transforming and enabling value creation networks, healthcare networks and businesses to thrive in the webbed economy and society. His email address is <Benoit.Montreuilecirrelt.ulaval.ca>. 